\title{
Control of doubly-fed induction generator, revisited
}

This paper was downloaded from TechRxiv (https://www.techrxiv.org).

\section{LICENSE}

CC BY 4.0

SUBMISSION DATE / POSTED DATE

21-06-2021 / 23-06-2021

CITATION

Hemami, Ahmad (2021): Control of doubly-fed induction generator, revisited. TechRxiv. Preprint. https://doi.org/10.36227/techrxiv.14818557.v1

$\mathrm{DOI}$

10.36227/techrxiv.14818557.v1 


\title{
Control of doubly-fed induction generator, revisited
}

\author{
Ahmad Hemami, \\ McGill University, Montreal, Que., Canada
}

\begin{abstract}
Most of today's commercial wind turbines are equipped with doubly fed induction generator (dfig) because of the advantages it offers. Many techniques have been proposed for the control of this class of wind turbine, some of which may be impracticable due to a large volume of required real time computations involved in their implementation. Thus, the subject is open to new ways of more efficient control strategies. In this paper a new way of looking at the control problem is studied based on the nature of how these machines work and how a controller manipulates their operation. The advantage is that a control scheme can be designed offline, and the results can then be implemented in a table-lookup. This is more suitable in practice. In an example some preliminary simulation results demonstrate the principle of this strategy.
\end{abstract}

Index Terms - Wind Power Generation, Control, Induction machine, DFIG

\section{INTRODUCTION}

Many commercial wind turbines today employ Wound Rotor Induction Machine (WRIM) for the generator, more known as Doubly Fed Induction Generator (DFIG). Although the trend is towards gearless turbines, this generator will continue to be used for many years to come because of its advantages that overweigh its disadvantages. Compared with squirrel cage machine the main advantage is that it can continue generation at a much wider range of wind speeds, at which a cage machine must stop. In addition, a DFIG can behave as a synchronous machine in the sense that the active and reactive power can be independently controlled, thus it is possible to adjust the output power factor. A third advantage is the possibility of torque control, as used in practice by some WT manufacturers. For wind turbines this flexibility allows a much better adaptation to the variation in the wind speed for maximum power harness, or for smoothing out the sudden torque changes experienced by the main shaft.

In industry, control of a turbine is mainly according to the power curve defined for a turbine based on the power capacity of the turbine generator. Part of this control action involves pitching the blades for limiting the power grasp from wind, based on wind speed. This is from the turbine side, and the controller determines the turbine speed. From the generator side, the generator is subject to a variable input speed, and it is necessary to regulate its operation for maximum output, considering the other criteria such as power factor or the shaft torque. This is performed through controlling the stator and rotor currents. The technique and the details of how it is implemented in any particular turbine is, however, a proprietary of the manufacturer.

In the academia and research community, nonetheless, many control design techniques are proposed for various objectives, such as active power control, reactive power control, torque control and the like. In the literature much has been said about different techniques for formulation of the control problem and regulating the behavior of DFIG. The studies involve many cases of laboratory experimentation [1], [2], [3], [4], or simulation [5], [6], [7]. In a commercial system the safe operation and protection of the system is also of primary importance and the required measurements and actions are embedded with turbine control algorithms.

Most of the control techniques proposed are based on vector control [8], which allows a virtual transformation from 3phase $\mathrm{AC}$ to a virtual $\mathrm{DC}$ equivalent for a machine. In this way, two current components are obtained, one for generating torque and the other for generating a magnetic field, similar to a DC machine. The bottom line in all the approaches, as exemplified by the references, is a manipulation of the generator stator and rotor currents.

In this paper, the control strategy is looked at from a different angle. We consider the effect of the action of a controller to the generator, which ultimately boils up to manipulation of the rotor winding current.

\section{GOVERNING EQUATIONS}

In all analytical work the knowledge about the relationships governing the function of an induction machine is necessary. Figure 1 is helpful for understanding the magnetic relationships, as well as the temporal (phase) relationships between the stator and rotor currents and voltages. The figure corresponds to phasor representation of magnetic flux and currents for one phase of a three-phase machine, but the other phases are repeat of the same thing with a spatial difference. In this figure the vectors denote the instantaneous positions of the maxima of the assumed sinusoidal waveforms of magnetic fluxes and currents. Figure 1 is based on the following relationships and according to [10]

$\lambda_{s}=\lambda_{m}+L_{s l} i_{s}$

$\lambda_{r}=\lambda_{m}+L_{r l} i_{r}$ 
$\lambda_{m}=L_{m} i_{m}$

$i_{m}=i_{s}+i_{r}$

where $\lambda_{\mathrm{m}}$ is the air gap magnetic flux, $\lambda_{\mathrm{s}}$ is the stator magnetic flux and $\lambda_{\mathrm{r}}$ is the rotor magnetic flux. $L_{s l}$ and $L_{r l}$ are, respectively, the stator and rotor flux leakage inductances. $L_{m}$ is the magnetizing inductance leading to the airgap flux.

In the above equations

$L_{s}=L_{s l}+L_{m}$
$L_{r}=L_{r l}+L_{m}$

The following are the fundamental equations relating the stator, airgap and rotor magnetic fluxes in terms of the stator and rotor currents.

$$
\begin{aligned}
& \lambda_{s}=L_{s} i_{s}+L_{m} i_{r} \\
& \lambda_{r}=L_{m} i_{s}+L_{r} i_{r}
\end{aligned}
$$

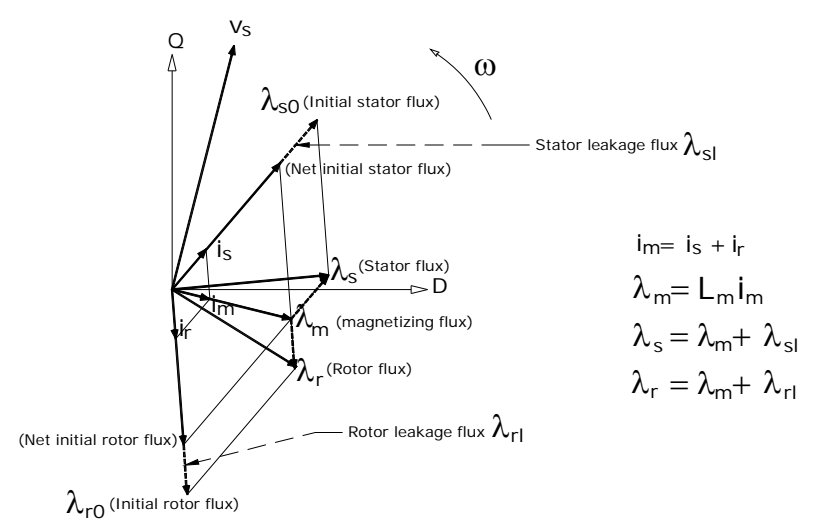

Fig. 1 Magnetic flux - current relationships

As shown in figure 1, when first a machine is connected to electricity the magnetic field developed is in phase with the current developing it. Similarly, the initial magnetic field of the rotor is in phase with the rotor current. But, as the interaction between the two fields settles the mutual magnetic field $\lambda_{\mathrm{m}}$ is common between them, and the equations must hold.

The torque developed on the shaft of an induction machine is a function of the three aforementioned magnetic fluxes and the angles between them. The following equations express the torque.

$\tau=k_{1} \lambda_{r} \lambda_{s} \sin \delta_{s r}$

$\tau=k_{2} \lambda_{s} \lambda_{m} \sin \delta_{s}$

or

$\tau=k_{3} \lambda_{r} \lambda_{m} \sin \delta_{r}$ where $\delta_{s r}$ is the angle between $\lambda_{\mathrm{s}}$ and $\lambda_{\mathrm{r}}, \mathrm{k}_{1}, \mathrm{k}_{2}$ and $\mathrm{k}_{3}$ are constants that depend on the parameters of a machine. Similarly, $\delta_{\mathrm{s}}$ and $\delta_{\mathrm{r}}$ are the angles between the air gap flux linkage $\lambda_{m}$ and stator flux and rotor flux linkages, respectively, as illustrated in figure 2. Similar to fluxes, the angles $\delta$ 's are functions of the stator and rotor currents, which in turn are functions of the applied voltage, frequency and the loading of a machine (which determines the machine slip).

It is to be noted, also, that the difference in time between the moment $v_{s}$ is at its peak and the moment $\lambda_{m}$ is at its peak is such that the angle between $\mathrm{v}_{\mathrm{s}}$ and $\lambda_{\mathrm{m}}$ is approximately $90^{\circ}$. This property is later on used for derivation of certain relationships.

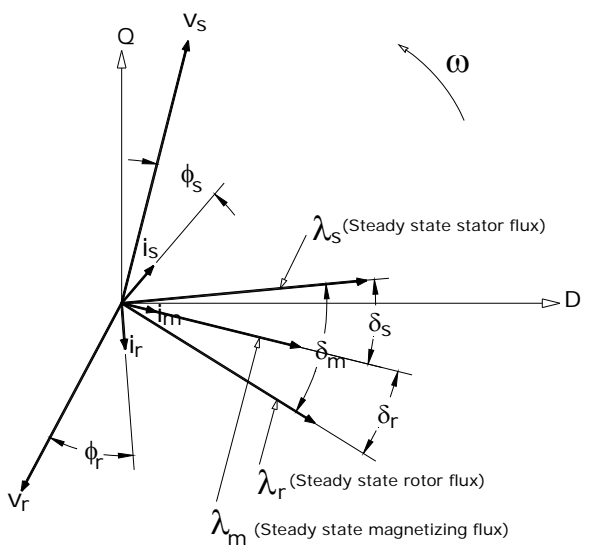

Fig. 2 Definition of angles

\section{CONTROL OF DOUBLY FED INDUCTION MACHINE, PRELIMINARY DISCUSSION}

In addition to the main function as a generator a doubly fed induction machine is controlled [11] for: Independent control of active and reactive power, (thus power factor control) [12], [13], or torque control [14], [15], or a combination of both [16]. Most of the control techniques proposed use vector control, but other techniques are also considered [17], [18]. General discussion for control of these machine can be found in [8], [19] and [20].

In a DFIG, implementation of any control strategy is through a manipulation of the rotor winding current. In wind turbines when the wind speed is sufficiently high the power grasp from the turbine can be entirely given to the grid through the stator. But, with further increase in wind speed, a part of the power can be taken from the rotor. At this time the power grasp by the turbine is beyond the generator stator capacity. How much of the power is to be taken by the rotor? This is where a control strategy can determine the proportion, based on taking into account other criteria (Mainly, power factor correction and torque control). This is the super-synchronous operation of the generator. 
On the other hand, when the wind speed is below a certain limit, a dfig runs at sub-synchronous speed and continues generation. Thus, based on the wind speed a dfig must switch from super-synchronous speed to sub-synchronous and vice versa.

Practically, the common method for allowing taking energy from the rotor winding or delivering energy to it (for subsynchronous operation) is having power converters. The reason is to change the voltage and frequency of the rotor output to that of the grid, or vice versa.

If the synchronous speed of a machine is $\mathrm{N}_{\mathrm{s}} \mathrm{rpm}$ and the rotor speed is $\mathrm{N}_{\mathrm{r}} \mathrm{rpm}$, then their associated frequencies (in radians per second) are

$\omega_{\mathrm{s}}=\frac{2 \pi \mathrm{N}_{\mathrm{s}}}{60}$ and $\omega_{r}=\frac{2 \pi N_{r}}{60}$

and the frequency of the voltage in the rotor winding is

$\omega_{\text {slip }}=\omega_{s}-\omega_{r}$

Then the machine slip is

$s=\frac{N_{s}-N_{r}}{N_{s}}=\frac{\omega_{s}-\omega_{r}}{\omega_{s}}$

and the rotor current frequency can also be expressed as

$\omega_{\text {slip }}=\omega_{s}-\omega_{r}=\frac{\omega_{s}-\omega_{r}}{\omega_{s}} \times \omega_{s}=s \omega_{s}$

For sub-synchronous operation $s$ is positive and for supersynchronous it is negative.

Since $\mathrm{s}$ is small in magnitude (less than 0.03 typically) the rotor winding has a very low frequency. The arrangement for a wind turbine DFIG generator is two back-to-back converters connected together by a capacitor (voltage source) or an inductor (current source). This is schematically depicted in figure 3. Based on the requirement (depending on the wind speed) each converter can function as a rectifier or an inverter, where the other converter does the reverse. In this way, the voltage and frequency of the rotor output can be brought at those of the stator level, or conversely a low frequency $\mathrm{AC}$ with the appropriate voltage can be injected to the rotor winding.

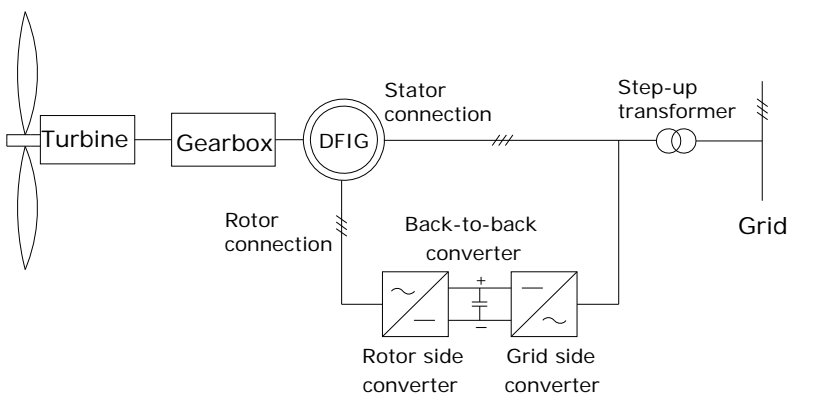

Fig. 3 Common implementation of back-to back converters with DFIG in wind turbines
Dealing with real values of voltages and currents for the purpose of deriving control schemes or implementing them is cumbersome. For this reason, in order to better manage the equations for torque and power in terms of the applied voltage, frequency and current, a set of two transformations are performed on the measured values of these variables. The first one, called Park, Clarke, or dq0 transform, converts a three-phase system to a virtual two axis system. In this way the induction machine resembles a DC machine in which the field and armature windings can be independently controlled. The coordinates of the two-axis system are commonly called $\mathrm{d}$-axis and $\mathrm{q}$-axis, $\mathrm{d}$ referred to as the direct coordinate and $\mathrm{q}$, at $90^{\circ} \mathrm{CCW}$ from $\mathrm{d}$, as the quadrature coordinate. A second transformation is also necessary for expressing conversion between two coordinate systems with an angle between them. For instance, coordinates attached to rotor and coordinates attached to stator magnetic fluxes, which are not in phase. Details of this transformations are available in the literature and are not discussed here.

After the variables are expressed in dq-coordinates equations governing the relationships between the voltage, current and the developed magnetic flux are

$$
\begin{aligned}
& v_{s d}=R_{s} i_{s d}+\frac{d}{d t} \lambda_{s d}-\omega_{s} \lambda_{s q} \\
& v_{s q}=R_{s} i_{s q}+\frac{d}{d t} \lambda_{s q}+\omega_{s} \lambda_{s d} \\
& v_{r d}=R_{r} i_{r d}+\frac{d}{d t} \lambda_{r d}-\left(\omega_{s}-\omega_{r}\right) \lambda_{r q} \\
& v_{r q}=R_{r} i_{r q}+\frac{d}{d t} \lambda_{r q}+\left(\omega_{s}-\omega_{r}\right) \lambda_{r d}
\end{aligned}
$$

As can be understood, $\lambda_{s d}, \lambda_{s q}, \lambda_{r d}$ and $\lambda_{r q}$ are the direct and quadrature components of the stator and rotor magnetic flux linkages, respectively. The same definition applies to the dand q-components of the stator and rotor voltages and currents. $R_{S}$ and $R_{r}$ are the stator and rotor winding resistances, respectively.

Furthermore, equations (7) and (8) assume the forms

$$
\begin{aligned}
& \lambda_{s d}=L_{s} i_{s d}+L_{m} i_{r d} \\
& \lambda_{s q}=L_{s} i_{s q}+L_{m} i_{r q} \\
& \lambda_{r d}=L_{m} i_{s d}+L_{r} i_{r d} \\
& \lambda_{r q}=L_{m} i_{s q}+L_{r} i_{r q}
\end{aligned}
$$

and the relationships for the electromagnetic torque and power are

$$
\begin{aligned}
\tau & =\frac{3}{2} p L_{m}\left(i_{s q} i_{r d}-i_{s d} i_{r q}\right) \\
P & =\frac{3}{2}\left(v_{s d} i_{s d}+v_{s q} i_{s q}\right) \\
Q & =\frac{3}{2}\left(v_{s q} i_{s d}-v_{s d} i_{s q}\right)
\end{aligned}
$$


where $p$ is the number of pairs of poles of the machine (stator), $\mathrm{P}$ is the active power and $\mathrm{Q}$ is the reactive power.

\section{A NEW LOOK TO THE DFIG CONTROL}

A closer look at what happens in the control of a doubly fed induction machine reveals that any control action, indeed, is performed by manipulating the rotor current. The rotor current as a result of its natural behavior is a (sinusoidal) waveform with a frequency of $\omega_{\text {slip }}$ as define by equations (12-14).

No matter what philosophy drives the control scheme for a variable speed turbine with DFIG, we notice that:

1- The power to be extracted from the generator at each wind speed is determined based on the turbine power curve.

2- How much power is to be taken from the rotor is determined based on a pre-scheduled program by the turbine manufacturer. This is true also for the power to be injected to the rotor in case of sub-synchronous operation.

3- The rotational speed of a turbine is determined based on the maximization of the power coefficient, which depends on the wind speed (through tip speed ration), too.

4- The frequency of the rotor current/voltage $\left(\omega_{\text {slip }}\right)$ depends on the rotational speed and the synchronous speed; thus, it depends on the wind speed in light of 3 .

5 - The maximum voltage in the rotor winding depends on the generator physical (electrical) properties.

6- The actual rotor voltage is proportional to the maximum rotor voltage and approximately changes linearly with slip speed. Thus, depends on the rotor speed, which depends on the wind speed (in light of 3 ).

From the above facts, it can be seen that the wind speed defines the proper values for various variables, including the current in the rotor winding, which determines the torque on the shaft.

In the super-synchronous operation, the power that is taken from the rotor determines the rotor current. The frequency is not changed by this power taken from the rotor. But it can introduce a phase difference between rotor voltage and rotor current. In the sub-synchronous operation, the power that is injected to the rotor winding can be out of phase with the rotor voltage (depending on firing angle).

The rotor current to be manipulated, thus, has a known frequency $\omega_{\text {slip }}$, at each instant of time, as dictated by the wind speed and the gearbox ratio. This manipulation is either injecting a voltage to the rotor winding or taking power from it. Both of these actions imply adding a waveform to the already present waveform of the rotor current. As such, the waveform of the rotor current at a given time can be assumed to be in the form of

$i_{r}=\mathrm{A} \cos \left(\omega_{\text {slip }} t\right)$ $i_{\text {cont }}=\mathrm{B} \cos \left(\omega_{\text {slip }} t+\gamma\right)$

$\mathrm{A}$ and $\mathrm{B}$ depend on the machine parameters; $\mathrm{B}$ is smaller than $\mathrm{A}$, and preferably equal to A for super-synchronous operation. It can be larger than A for sub-synchronous case. $\gamma$ is, indeed, the firing angle of the IGBT's (or thyristors) in the back-toback converters. Then the resultant current in the rotor is a waveform with the same frequency the amplitude of which is modified and has a phase difference with respect to the original rotor current, as it is easy to do the math and observe that

$i_{r}+i_{\text {cont }}=\frac{A+B \cos \gamma}{\cos \eta} \cos \left(\omega_{\text {slip }} t+\eta\right)$,

where $\eta=\tan ^{-1} \frac{B \sin \gamma}{A+B \cos \gamma}$

A comparison of equations (26) and (28) indicates that the original rotor current has been multiplied by $\frac{A+B \cos \gamma}{\cos \eta}$ and it is shifted by the angle $\eta$.

The relationship between the control signal phase angle $\gamma$ and the resulting shift in the rotor current $\eta$ is

$\gamma=\eta+\sin ^{-1}\left(\frac{A}{B} \sin \eta\right)$

In particular, $\eta$ is zero if $\gamma=0$, and $\gamma=2 \eta$ if $\mathrm{B}=\mathrm{A}$.

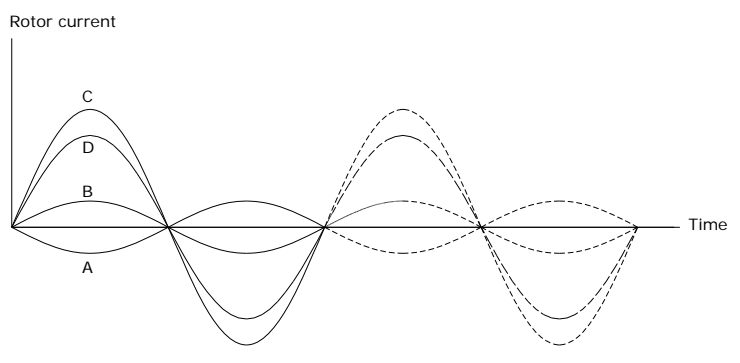

Fig. 4. Rotor current (D) as a result of injecting waveform C when original current was waveform A, for $\gamma=0$

The relationship between rotor current and the induced voltage in the rotor is shown in equations (17) and (18); and equations (21) and (22) reveal that the rotor magnetic flux is affected by both stator and rotor currents. Furthermore, the effect of rotor current on the machine torque is depicted in equation (23). In order to use these relationships, and also equations (24) and (25) for power, it is first necessary to define the frame of reference with respect to which the equations must be expressed. The most common reference frames are those attached to the magnetic flux of the rotor, the stator, or the airgap. It is easy to show that [13] in the frame attached to the airgap

$i_{s q}+i_{r q}=0$.

(This immediately follows from equation (4), as graphically shown in Figure 5.)

and the waveform which is adding to it can be expressed as 


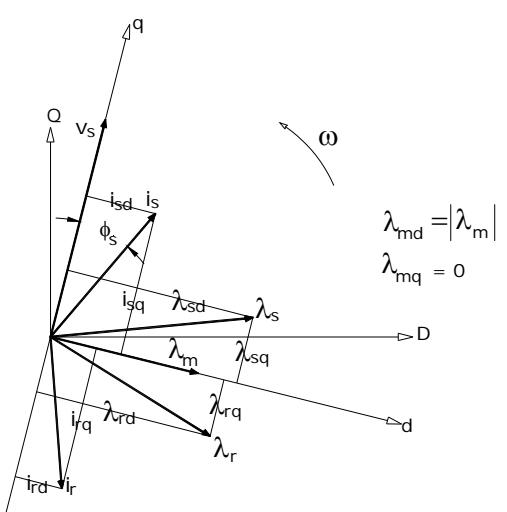

Fig. 5- dq-frame attached to air gap flux

It follows from equations (3), (4) and (30) that

$\lambda_{m}=L_{m}\left(i_{s d}+i_{r d}\right)$

Furthermore, since the direction of $v_{s}$ is almost perpendicular to $\lambda_{\mathrm{m}}$, then $v_{\text {sd }} \cong 0$, which leads to

$P=\frac{3}{2}\left(v_{s q} i_{s q}\right)$

in light of equation (24) and

$Q=\frac{3}{2}\left(v_{s q} i_{s d}\right)$

in light of equations (25).

Figures 4 and 5 help to visualize the effect of injecting a current to the machine rotor winding. Figure 4 corresponds to $\gamma=0$. Figure 5 corresponds to shifting phase, and indicates that if $i_{r}$ is rotated clockwise, then in order to satisfy the governing equations $i_{s}$ must rotate counterclockwise. The effect is that (a) the phase angle $\varphi_{s}$ becomes smaller (power factor increases) and (b) the torque increases, since $\delta_{s r}$ becomes larger in size. Thus, by a proper shift in the rotor current it is possible to influence the reactive power or the torque, as desired.

The above observation allows a different way of controlling the behavior of a DFIG. Instead of real time calculations for implementing a control strategy to determine the rotor current and other variable, a set of predefined (offline) values for the current to be injected to the rotor winding may be formed in a table-lookup for the turbine controller. In practice, this is easier to implement and preferred to do real time calculations.

\section{SIMULATION RESULTS}

Here some results are demonstrated in an example for a randomly selected machine. The following data correspond to an $18.65 \mathrm{~kW}$ machine with two pairs of poles per phase (12 total poles), $60 \mathrm{~Hz}$, with nominal voltage or $460 \mathrm{~V}$. At the time of the operating conditions the machine works at $\mathrm{pf}=0.9$. The reason for selecting such a tiny machine is solely the availability of the machine data.

$R_{s}=0.641 \Omega, R_{r}=0.332 \Omega$,

$L_{s l}=2.93 \mathrm{mH}, L_{r l}=1.67 \mathrm{mH}, L_{m}=69.76 \mathrm{mH}$

From the above numbers it follows from equations (5) and (6) Synchronous speed $=1800 \mathrm{rpm}, \omega_{\mathrm{s}}=188.5 \mathrm{rad} / \mathrm{s}, \quad \lambda_{\mathrm{s}}=$ $72.7 \mathrm{mH}, \lambda_{\mathrm{r}}=71.43 \mathrm{mH}, \varphi_{\mathrm{s}}=\cos ^{-1}(0.9)=25.84^{\circ}$

Also, stator current $=45 \mathrm{~A}$ and torque $=99 \mathrm{Nm}$ (for three-phase machine).

If the frame attached to the airgap flux is oriented with the daxis of the dq-frame, after a Clarke transformation the values corresponding to the above data are

$v_{s d}=0 \quad v_{s q}=460 \mathrm{~V}$,

$i_{s}=10 A, i_{s d}=10 \sin 25.84=4.36 A, i_{s q}=$

$10 \cos 25.84=9 A$,

Then it follows from equation (7), (8), (30) and (31) that

$i_{r q}=9 A, \quad i_{r d}=13.15 A, \quad i_{r} \cong 16 A, \lambda_{\mathrm{m}}=1.2215 \mathrm{~Wb}$

Assuming that all the above given values correspond to a state of the machine reached based on the input wind speed, and constant grid voltage and frequency, we want to modify the power factor (which implies changes in active power $\mathrm{P}$ and reactive power Q) by shifting the rotor waveform according to equation (28) and without increasing/decreasing the stator current $\left(i_{s}\right)$.

Table 1

Effect of variation of $\eta$ on torque and power factor

\begin{tabular}{|c|c|c|c|c|c|c|c|c|c|c|c|c|}
\hline$\eta$ & $\Delta \varphi$ & $\mathrm{I}_{\mathrm{r}}$ angle & $\mathrm{I}_{\mathrm{s}}$ angle & $\lambda_{\mathrm{r}}, \mathrm{Wb}$ & $\lambda_{\mathrm{s}}, \mathrm{Wb}$ & $\delta_{\mathrm{r}}\left(^{\circ}\right)$ & $\delta_{\mathrm{s}}\left(^{\circ}\right)$ & $\delta_{\mathrm{m}}\left(^{\circ}\right)$ & $\tau(\mathbf{N m})$ & $\mathrm{P}(\mathrm{W})$ & $\mathrm{Q}, \mathrm{VAR}$ & Pf $(\mathbf{\%})$ \\
\hline $\mathbf{0}$ & 0 & $-34.4^{\circ}$ & $64.2^{\circ}$ & 1.2346 & 1.244 & -0.69 & 1.23 & 1.92 & $\mathbf{3 3}$ & 6210 & 3007 & $\mathbf{9 0}$ \\
\hline $\mathbf{1}^{\circ}$ & $3.14^{\circ}$ & $-35.4^{\circ}$ & $67.3^{\circ}$ & 1.2433 & 1.233 & -0.71 & 1.26 & 1.97 & $\mathbf{3 3 . 8}$ & 6367 & 2658 & $\mathbf{9 2 . 3}$ \\
\hline $\mathbf{2}^{\circ}$ & $6.67^{\circ}$ & $-36.4^{\circ}$ & $71.0^{\circ}$ & 1.2431 & 1.231 & -0.73 & 1.29 & 2.02 & $\mathbf{3 4 . 6}$ & 6530 & 2250 & $\mathbf{9 4 . 5}$ \\
\hline $\mathbf{3}^{\circ}$ & $11.08^{\circ}$ & $-37.4^{\circ}$ & $75.4^{\circ}$ & 1.2428 & 1.229 & -0.745 & 1.32 & 2.07 & $\mathbf{3 5 . 4}$ & 6674 & 1742 & $\mathbf{9 6 . 8}$ \\
\hline $\mathbf{4}^{\circ}$ & $17.42^{\circ}$ & $-38.4^{\circ}$ & $81.7^{\circ}$ & 1.2425 & 1.226 & -0.762 & 1.36 & 2.12 & $\mathbf{3 6 . 2}$ & 6828 & 995 & $\mathbf{9 8 . 9}$ \\
\hline
\end{tabular}


In the simulation the vector $i_{r}$ has been rotated CW (without a change in magnitude) for as far as the power factor can be improved to near unity. Since the rotor current stays constant and the airgap flux is maintained constant according to the discussion for figure 3 , the stator current stays constant. Table 1 shows the results for the increments of one degree for $\eta$, which corresponds with one degree rotation of $i_{r}$. As it can be seen, for each one degree of rotation of $i_{r}, i_{s}$ has a larger $\mathrm{CCW}$ rotation, as a result of which $\varphi_{s}$ decreases. The table shows also the values for rotor and stator magnetic fluxes $\left(\lambda_{\mathrm{r}}\right.$ and $\left.\lambda_{\mathrm{s}}\right)$ and their angles with respect to airgap flux $\lambda_{\mathrm{m}}$.

\section{SUMMARY}

This paper considers a new way of implementing control action to a doubly fed induction generator in wind turbines. The analysis is based on the fact that for the control of this class of induction machines the rotor winding is manipulated by either taking current from it or injecting current to it, depending on the wind speed and machine characteristics. This fact suggests that instead of real time calculations for direct control, the control strategy can be based on observing the effect of various currents injected to the rotor, for any given situation defined by the wind speed and other associated information. This approach can be implemented through a table look-up, which is more convenient from a practical viewpoint.

Some results are shown by simulation for power factor correction, using this approach to an exemplified machine.

\section{REFERENCES}

[1] Pena R, Clare J C, Asher G M. "Doubly fed induction generator using back-to-back PWM converters and its application to variable-speed wind-energy generation", Electric Power Applications, IEE Proceedings 143, 3: 231241, 1996.

[2] Pena R, Clare J C, Asher G M. “A doubly fed induction generator using back-to-back PWM converters supplying an isolated load from a variable speed wind turbine," IEE Pro. Electric Power Appl. 143 (5): 380-387, 1996.

[3] Chowdhury B H , Chellapilla S. "Double-fed Induction Generator Control for variable speed wind power generation," Electric Power Systems Research 76: 786-800, 2006.

[4] Serban I, Klumpner D, Blaabjerg F, Boldea I. "Sensorless control of wound rotor induction generator (WRIG) for wind power applications: the experimental test platform". Proc. 37th IEEE Power Electronics Specialists Conference (PESC '06) 48-55, 2006.

[5] Hofmann W, Thieme A. "Control of a double-fed induction generator for wind-power plants," Proc. Of Power Quality 275-282, 1988.
[6] Tang Y, Xu L. “A flexible active and reactive power control strategy for a variable speed constant frequency generating system," IEEE Trans Power Electronics 10(4): 472-478, 1995.

[7] Byeon G, Park I K, Jang G. "Modelling and control of a doubly-fed generator (DFIG) wind power generation system for real-time simulations,". J. Electrical Engineering \& Technology 5(1): 61-69, 2010.

[8] Vas, Peter. Vector control of AC machines, Oxford University Press, 1990

[9] Smith G.A. Nigim K.A. "Wind-energy recovery by a static Scheribus induction generator". IEE Proc. C 128, (6): 317-324, 1981 .

[10] Krause, Paul C., Analysis of electric machinery, McGraw Hill, 1986.

[11] Muller S, Diecke M, DeDoncker R W. "Doubly fed induction generator systems for wind turbines", IEEE Industry Applications Magazine pp 26-33, 2002,(May/June).

[12] Kayikci M, Milanovic J V. "Reactive power control strategies for DFIG-based plants", IEEE Trans Energy Conv. 22 (2): 389-396

[13] Yamamoto M, Motoyoshi O. "Active and reactive power control for doubly-fed wound rotor induction generator", IEEE Transactions on Power Electronics, 6, (4): 624 - 629, 1991.

[14] Arnalte S, Bourgos J.C, Rodrigues-Amenedo J.L.'Direct torque control of a doubly-fed induction generator for variable speed wind turbines", Electric Power Components and Systems, 30 (2) pp 199-216, 2002.

[15] Bonnet F, Vidal P.E, Pietrazak-David M, "Direct torque control of doubly fed induction machines" Bulletin of the Polish Academy of Sciences, 54(3) pp 307-324, 2006.

[16] Brekken T, Mohan, N. "A novel doubly-fed induction wind generator control scheme for reactive power control and torque pulsation compensation under unbalanced grid voltage conditions" Power Electronics Specialist Conference, Vol 2: 760- 764, 2003.

[17] Salameh Z M, Kazda L F. "Analysis of the double output induction generator using direct three-phase model" IEEE Trans. Energy Conv. EC-2 (2):175-181, 1987.

[18] Thangaraju I, Madheswaran M. "Performance analysis of double inverter fed wound rotor induction motor using fuzzy and PI controller", Int. J. Computer Applications 1 (20): 80-89, 2010.

[19] Trzynadlowski A. Control of induction motors, Academic Press, 2001.

[20] Boldea, Ion, Variable Speed Generators, CRC Press, 2006. 